\title{
Propostas de melhorias em um método de avaliação de sistemas de gestão de segurança e saúde no trabalho
}

\author{
Tarcisio Abreu Saurin ${ }^{\mathrm{a}, *}$, Guido César Carim Júnior ${ }^{\mathrm{b}}$ \\ a,*saurin@ufrgs.br, UFRGS, Brasil \\ bjrguido@producao.ufrgs.br, UFRGS, Brasil
}

\begin{abstract}
Resumo
Este artigo apresenta propostas de melhorias em um método de avaliação de sistemas de gestão da segurança e saúde no trabalho, o qual tem a engenharia de resiliência (ER) como filosofia e foi originalmente aplicado em um estudo de caso em uma metalúrgica. Quatro modificações foram propostas em relação à versão original: (a ) diretrizes para que a avaliação do atendimento aos princípios da ER seja realizada de modo sistemático; (b) diretrizes para elaborar um plano de ação resultante da avaliação; (c) reorganização dos instrumentos de coleta de dados, para facilitar sua aplicação por usuários com pouca experiência no método; e (d) procedimentos para facilitar a atribuição de pontuações aos itens avaliados. A implantação dessas propostas é ilustrada por meio de um estudo de caso de aplicação do método em uma distribuidora de energia elétrica. As modificações propostas não foram consequência das particularidades do estudo de caso, o que é um indicativo da viabilidade de aplicação do método em outros setores, além da indústria da manufatura.
\end{abstract}

Palavras-chave

Gestão da segurança e saúde no trabalho. Engenharia de resiliência. Eletricistas.

\section{Introdução}

As boas práticas de gestão da segurança e saúde no trabalho (SST) normalmente são prescritivas e possuem princípios implícitos. Contudo, uma vez que não sejam conhecidos os princípios subjacentes às práticas de gestão, torna-se mais difícil manter o sistema de gestão de SST (SGSST) continuamente adequado às mudanças no sistema sócio-técnico em que a organização está inserida (REIMAN; OEDEWALD, 2009).

A adoção de um conjunto de princípios também é essencial, uma vez que isso determina quais dimensões de desempenho são priorizadas. Como exemplo da importância dessa definição, diversos estudos indicam que conclusões substancialmente distintas podem ser obtidas a partir de métodos de investigação de acidentes com diferentes orientações teóricas (LUNDBERG; ROLLENHAGEN; HOLLNAGEL, 2009).

Nesse contexto, a engenharia de resiliência (ER) vem sendo apontada como um novo paradigma de gestão da SST (HOLLNAGEL; WOODS; LEVESON, 2006; HOLLNAGEL; NEMETH; DEKKER, 2008), que tem como objetivo articular conceitos, princípios e métodos que até então vinham sendo usados de modo fragmentado pelas empresas e acadêmicos e sem uma fundamentação teórica explícita. A ER enfatiza a compreensão de como o sucesso é obtido, como as pessoas aprendem e se adaptam criando a segurança em um ambiente com perigos, tradeoffs e múltiplos objetivos (HOLLNAGEL; WOODS; LEVESON, 2006). Embora isoladamente cada um dos princípios da ER não constitua uma inovação teórica, a articulação conjunta de todos em uma teoria de gestão da SST com orientação sociotécnica é potencialmente sua maior contribuição. De acordo com Hollnagel, Nemeth e Dekker (2008), a ER propõe a reinterpretação das boas práticas de SST, ao invés de descartá-las.

Os métodos de avaliação dos SGSST são uma das práticas que vêm sendo reinterpretadas sob o 
paradigma daER(HALE;GULDENMUND;GOOSSENS, 2006; COSTELLA; SAURIN; GUIMARÃES, 2009), sendo focalizados no presente artigo. Em particular, este trabalho aborda o método de avaliação de SGSST desenvolvido por Costella, Saurin e Guimarães (2009), identificado pela sigla MASST. Tal método foi escolhido porque explicitamente ele associa os requisitos de avaliação do SGSST aos princípios da ER, e pelo fato de que os autores deste artigo vêm aplicando o mesmo em algumas empresas, havendo, portanto, disponibilidade de dados empíricos acerca de seu uso.

0 método foi originalmente desenvolvido e testado em uma metalúrgica, sendo que uma segunda aplicação foi realizada por Carim Júnior, Silva e Saurin (2008) em uma escola de aviação civil de pequeno porte. Nesse segundo estudo, foi verificado que alguns requisitos estabelecidos pelo MASST não eram familiares para os instrutores de voo e diretores da escola de aviação. Tal dificuldade decorre do MASST ter sido desenvolvido no contexto da indústria da manufatura, sendo necessário investigar sua adequação a outros contextos. Carim Júnior, Silva e Saurin (2008) também perceberam subjetividade excessiva na atribuição de notas a cada item. Além disso, as aplicações já realizadas do MASST não resultaram em diretrizes para que a avaliação do atendimento aos princípios da ER seja realizada de forma sistematizada. Embora os estudos de Costella, Saurin e Guimarães (2009) e Carim Júnior, Silva e Saurin (2008) tenham apresentado análises do atendimento aos princípios da ER, a falta de diretrizes para realizar tais análises a torna difícil de ser replicada por usuários com pouca experiência no método e prejudica seu aprofundamento conceitual.

Desse modo, este estudo tem como objetivo propor melhorias no MASST, enfatizando quatro aspectos:

(a) diretrizes para avaliar o atendimento aos princípios da ER;

(b) diretrizes para facilitar o uso dos instrumentos de coleta de dados por usuários com pouca experiência no método, situação que tende a se normalizar na medida em que mais aplicações são realizadas;

(c) recomendações para reduzir a subjetividade na atribuição de notas aos itens avaliados; e

(d) diretrizes para a elaboração de um plano de ação que oriente a implantação das oportunidades de melhoria identificadas por meio do MASST. Um estudo de caso de aplicação do MASST em uma distribuidora de energia elétrica é apresentado para ilustrar os aperfeiçoamentos propostos.

\section{Origens e princípios da ER}

Em relação à perspectiva adotada para controlar os perigos de natureza organizacional, a ER se baseia em estudos sobre organizações de alta confiabilidade (HRO, High Reliability Organizations) (WEICK; SUTCLIFFE, 2001). Tais estudos identificaram características de empresas que realizam atividades de alto risco em ambientes complexos e ainda assim mantêm excelentes índices de segurança e eficiência operacional. Contudo, os estudos sobre HRO enfatizam a descrição das características dessas organizações, sem aprofundar como estas podem ser projetadas e implantadas em outros contextos. De acordo com Dekker e Woods (2010), os estudos em ER constituem oportunidade para o desenvolvimento de métodos para projetar e gerenciar HRO.

A visão de cultura de segurança adotada por Reason (1997) também é alinhada com os princípios da ER na medida em que esse autor propõe que a cultura de segurança pode ser conscientemente projetada e gerenciada, devendo abordar quatro construtos: uma cultura de relatos de informações de SST, uma cultura de aprendizagem, uma cultura justa e uma cultura flexível. Similarmente ao que ocorre com os estudos de HRO, Reason (1997) também não desenvolveu uma agenda operacional para implantar os princípios sugeridos.

Sob a perspectiva do desempenho humano, a ER se baseia na Engenharia de Sistemas Cognitivos (ESC) (HOLLNAGEL; WOODS, 2005). A ESC adota a visão de que os projetistas devem ter uma imagem do desempenho cognitivo dos usuários de produtos e processos, ao invés de apenas uma imagem física e fisiológica deles (HOLLNAGEL; WOODS, 1999). Por sua vez, essa imagem cognitiva assume que 0 desempenho humano (por exemplo, decisões e ações) não pode ser explicado sem a forte consideração do contexto organizacional em que ele ocorre. De fato, a unidade de análise para a ESC não é nem o indivíduo nem a máquina, mas sim o sistema cognitivo correlacionado (joint cognitive system), definido como um conjunto homem-máquina que não deve ser analisado separadamente. 0 termo máquina é interpretado como qualquer artefato projetado para um uso específico, sendo que uma organização pode também ser considerada um artefato, embora de natureza social ao invés de física (HOLLNAGEL; WOODS, 2005). Ainda sob a perspectiva do desempenho humano, a ER assume que não faz sentido limitar a investigação de incidentes ao papel dos erros humanos, devendo ser enfatizada a compreensão das condições que levaram os operadores a realizar adaptações malsucedidas (DEKKER, 2002). 
A ER visa contribuir para a compreensão e melhoria da resiliência dos sistemas, seja em nível individual, de equipe ou organizacional (HOLLNAGEL; WOODS; LEVESON, 2006). Em quaisquer desses níveis, a resiliência possui três dimensões: (a) a capacidade de evitar que um acidente ocorra; (b) a capacidade de evitar que um acidente já ocorrido propague seus impactos; (c) a capacidade de recuperação ao estado normal, após um acidente (WESTRUM, 2006). Neste estudo, considera-se que a dimensão (a) da resiliência caracteriza sua ênfase proativa e que as dimensões (b) e (c) caracterizam sua ênfase reativa.

Diversos estudos têm proposto características e princípios de projeto de sistemas resilientes (HOLLNAGEL; WOODS; LEVESON, 2006; HOLLNAGEL; NEMETH; DEKKER, 2008). No presente artigo, são adotados os princípios propostos por Costella, Saurin e Guimarães (2009), visto que eles estão subjacentes aos itens do MASST. Tais princípios são apresentados a seguir:

(a) Comprometimento da alta direção: implica em que a SST seja um valor-chave da empresa, ao invés de uma prioridade eventual. A adoção desse princípio constitui um obstáculo às pressões de produção sobre a SST;

(b) Aprendizagem: a A ER enfatiza a aprendizagem a partir da análise do trabalho normal, em complemento à aprendizagem a partir de incidentes. Segundo esse princípio, o monitoramento dos procedimentos é tão ou mais importante do que o seu desenvolvimento, uma vez que isso contribui para reduzir a distância entre o trabalho como imaginado pelos gerentes e como realizado pelos operadores;

(c) Flexibilidade: uma vez que a ER assume que os erros são inevitáveis, o sistema deve ser flexível para resistir a eles e reconhecer que a gestão da variabilidade é tão importante quanto a sua redução. A meta dos projetistas deve ser reforçar a variabilidade que leva a resultados positivos e eliminar aquela que leva a eventos indesejados. Esse princípio também implica em que o pessoal operacional seja capaz e autônomo para tomar decisões importantes sem esperar por instruções dos gerentes;

(d) Consciência: todos os componentes do sistema devem estar conscientes do seu desempenho e do estado das barreiras contra acidentes em relação ao limite da perda de controle. A consciência permite antecipar mudanças nos riscos e avaliar os trade-offs entre segurança e produção.

\section{MASST}

O MASST permite a avaliação dos SGSST segundo três modalidades de auditoria: (a) estrutural, que avalia o sistema prescrito com base na análise de documentos; (b) operacional, que avalia o sistema real com base em entrevistas e observações; e (c) desempenho, que avalia os resultados dos indicadores da empresa. 0 método é constituído por 28 itens distribuídos entre sete critérios de avaliação (Quadro 1).

Quadro 1. Critérios e itens de avaliação do MASST.

\begin{tabular}{|c|c|c|c|c|c|c|}
\hline $\begin{array}{l}\text { 1. Planejamento } \\
\text { do sistema de } \\
\text { gestão }\end{array}$ & $\begin{array}{l}\text { 2. Processos } \\
\text { de produção }\end{array}$ & $\begin{array}{l}\text { 3. Gestão e } \\
\text { capacitação de } \\
\text { pessoas }\end{array}$ & $\begin{array}{l}\text { 4. Fatores } \\
\text { genéricos da } \\
\text { segurança }\end{array}$ & $\begin{array}{l}\text { 5. Planejamento } \\
\text { do monitoramento } \\
\text { de desempenho }\end{array}$ & $\begin{array}{l}\text { 6. Retroalimentação } \\
\text { e aprendizado }\end{array}$ & 7. Resultados \\
\hline $\begin{array}{l}\text { 1.1. Objetivos e } \\
\text { política do SGSST }\end{array}$ & $\begin{array}{l}\text { 2.1. Identificação } \\
\text { de perigos } \\
\text { de acidentes } \\
\text { e doenças } \\
\text { com enfoque } \\
\text { tradicional }\end{array}$ & $\begin{array}{l}\text { 3.1. Participação } \\
\text { dos trabalhadores }\end{array}$ & $\begin{array}{c}\text { 4.1. Integração } \\
\text { de sistemas de } \\
\text { gestão }\end{array}$ & $\begin{array}{l}\text { 5.1. Indicadores } \\
\text { reativos }\end{array}$ & $\begin{array}{l}\text { 6.1. Investigação de } \\
\text { incidentes }\end{array}$ & $\begin{array}{l}\text { 7.1. Desempenho } \\
\text { reativo }\end{array}$ \\
\hline $\begin{array}{l}\text { 1.2. Planejamento } \\
\text { do SGSST }\end{array}$ & $\begin{array}{l}\text { 2.2. Identificação } \\
\text { de perigos de } \\
\text { acidentes e } \\
\text { doenças com } \\
\text { enfoque na ER }\end{array}$ & $\begin{array}{l}\text { 3.2. Treinamento } \\
\text { e capacitação }\end{array}$ & $\begin{array}{c}4.2 . \\
\text { Gerenciamento } \\
\text { das mudanças }\end{array}$ & $\begin{array}{l}\text { 5.2. Indicadores } \\
\text { proativos }\end{array}$ & $\begin{array}{l}\text { 6.2. Investigação do } \\
\text { trabalho normal }\end{array}$ & $\begin{array}{l}\text { 7.2. Desempenho } \\
\text { proativo }\end{array}$ \\
\hline $\begin{array}{l}\text { 1.3. Estrutura e } \\
\text { responsabilidade }\end{array}$ & $\begin{array}{l}\text { 2.3. Avaliação de } \\
\text { riscos }\end{array}$ & & 4.3. Manutenção & $\begin{array}{l}\text { 5.3. Auditoria } \\
\text { interna }\end{array}$ & $\begin{array}{l}\text { 6.3. Ações } \\
\text { preventivas }\end{array}$ & \\
\hline $\begin{array}{l}1.4 . \\
\text { Documentação e } \\
\text { registros }\end{array}$ & $\begin{array}{l}\text { 2.4. Planejamento } \\
\text { de ações } \\
\text { preventivas } \\
\text { com enfoque } \\
\text { tradicional }\end{array}$ & & $\begin{array}{l}\text { 4.4. Aquisição e } \\
\text { contratação }\end{array}$ & & 6.4. Ações corretivas & \\
\hline $\begin{array}{l}\text { 1.5. Requisitos } \\
\text { legais }\end{array}$ & $\begin{array}{l}\text { 2.5. Planejamento } \\
\text { de ações } \\
\text { preventivas com } \\
\text { enfoque na ER }\end{array}$ & & $\begin{array}{l}\text { 4.5. Fatores } \\
\text { externos }\end{array}$ & & $\begin{array}{l}\text { 6.5. Condução da } \\
\text { análise crítica e } \\
\text { melhoria contínua }\end{array}$ & \\
\hline $\begin{array}{l}\text { 1.6. Compromisso } \\
\text { da alta direção }\end{array}$ & & & & & & \\
\hline
\end{tabular}


A aplicação do MASST ocorre por meio de um questionário, no qual para cada item de avaliação são explicitados a modalidade de auditoria; as fontes de evidências; os princípios da ER avaliados; os requisitos a serem avaliados nas alíneas do questionário. Como exemplo, a seguir é parcialmente apresentado o trecho do questionário referente ao item compromisso da alta direção:

\subsection{Abordagem: operacional}

Fontes de evidências: entrevista com representantes da alta direção (requisitos a, b, c, d, e, f), entrevista com representantes da gerência (requisitos a, b, c, d, e, f), entrevista com representantes do setor de SST (requisitos a, b, c, $d$, e, f) e entrevista com trabalhadores (requisitos a, b, c, e).

(a) Destacar se a alta direção participa dos esforços de SST e interage com as partes interessadas, demonstrando comprometimento e buscando oportunidades para o desenvolvimento do SGSST (comprometimento da alta direção e aprendizagem).

0 MASST inclui a possibilidade de que uma pontuação seja atribuída a cada item e cada critério, com base no sistema de pontuação adotado pelo Prêmio Nacional de Qualidade (FPNQ, 2006). Para cada item, dentre os critérios de 1 a 6 , deve ser definido o percentual que mais se aproxima da realidade observada, segundo os fatores de avaliação de enfoque (subdividido em adequação, proatividade, refinamento e inovação) e aplicação (subdividida em disseminação, continuidade e integração) (Quadro 2). Já os itens do critério 7 do MASST (resultados) devem ser avaliados com base nos fatores de relevância, nível atual e tendência, também definidos pelo PNQ para avaliar os resultados do sistema de gestão da qualidade.

0 MASST também apresenta recomendações operacionais para sua aplicação, tais como: (a) definir um avaliador líder; (b) negociar um cronograma de aplicação com os representantes da empresa; (c) iniciar a avaliação pela abordagem estrutural, seguida pela abordagem de desempenho e pela operacional - desse modo, os avaliadores podem conhecer o SGSST idealizado pela empresa e posteriormente verificar se ele está sendo colocado em prática, além de obterem mais subsídios para enriquecer as entrevistas. Todas essas recomendações foram seguidas no estudo de caso relatado neste artigo.

\section{Método de pesquisa}

A avaliação do SGSST da distribuidora de energia elétrica ocorreu durante 3 meses, incluindo as seguintes grandes etapas: (a) lançamento formal do projeto em um evento dirigido a diretores e funcionários; (b) coleta das evidências para avaliar cada item do MASST; (c) seminário envolvendo pesquisadores e representantes da empresa para validar os resultados; (d) apresentação dos resultados para a direção da empresa; (e) definição de ações resultantes da avaliação; e (f) entrevista com o diretor e vice-diretor do departamento de SST para identificar suas percepções quanto aos pontos positivos e negativos do MASST. Esses diretores foram escolhidos pois já eram os contatos dos pesquisadores durante a coleta de dados (por exemplo, eles auxiliaram no agendamento de entrevistas e monitoraram o cumprimento dos prazos previstos para a pesquisa), além de serem os principais representantes da área da empresa diretamente enfatizada na avaliação. As fontes de evidências utilizadas para aplicação do MASST incluíram documentos (relatórios de investigação de acidentes), observações diretas (por exemplo, acompanhamento do técnico de segurança durante inspeções do trabalho das equipes nas ruas) e entrevistas (Tabela 1). A equipe de avaliadores foi composta por oito pesquisadores, com formações diversas: 3 engenheiros; 1 fisioterapeuta; 1 médica do trabalho; 1 bacharel em ciências aeronáuticas; 2 graduandos em engenharia de produção. Apenas dois desses avaliadores tinham participado dos estudos anteriores de aplicação do MASST, sendo que um deles assumiu o papel de examinador líder e forneceu um treinamento, com cerca de 4 horas de duração, aos outros examinadores quanto ao conteúdo e procedimentos para aplicar o MASST, bem como acerca dos princípios da ER.

A empresa investigada distribui energia elétrica para uma população de cerca de 3 milhões de habitantes e tem seu patrimônio acionário dividido entre o governo estadual (acionista majoritário), o governo federal e uma pequena parcela de investidores da iniciativa privada. A empresa está sediada em 72 municípios, abrangendo $73.627 \mathrm{~km}^{2}$. Para atender a tal demanda, possui $47.000 \mathrm{~km}$ de redes urbanas e rurais e conta com cerca de 2.000 funcionários, além de um contingente variável de eletricistas terceirizados que realizam manutenções corretivas e obras de expansão da rede.

As principais atividades de uma típica distribuidora de energia elétrica, como era o caso da empresa estudada, são: (a) projeto, construção e 


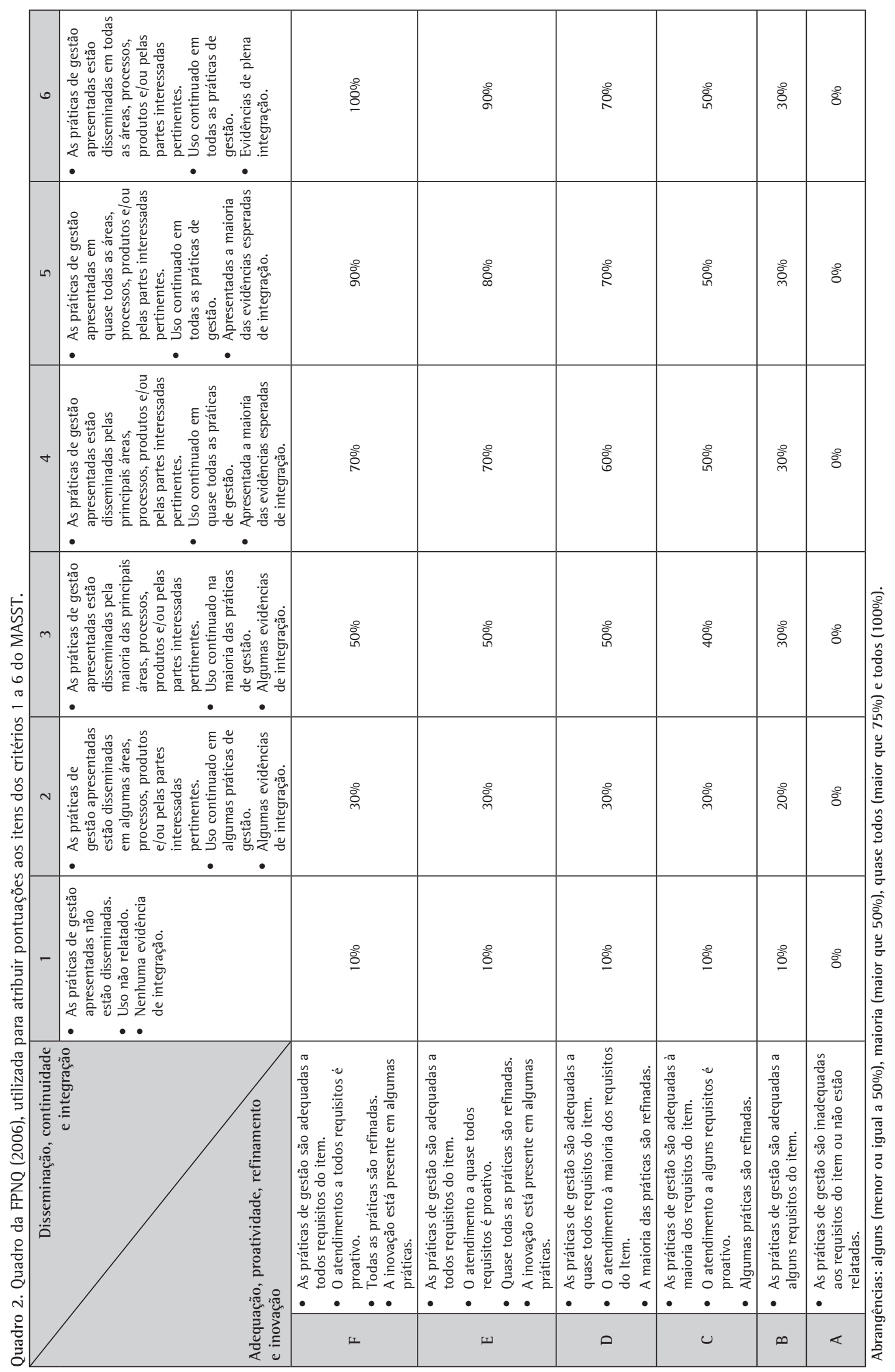


Tabela 1. Entrevistas realizadas para aplicação do MASST.

\begin{tabular}{|c|c|c|}
\hline Entrevistados & $\begin{array}{l}\text { Número de } \\
\text { entrevistados }\end{array}$ & $\begin{array}{c}\text { Duração das } \\
\text { entrevistas }\end{array}$ \\
\hline Presidente & 1 & $18 \mathrm{~min} 18 \mathrm{~s}$ \\
\hline Diretor administrativo & 1 & $37 \min 25 s$ \\
\hline $\begin{array}{l}\text { Chefe da divisão de } \\
\text { recursos humanos }\end{array}$ & 1 & $50 \min 56 s$ \\
\hline $\begin{array}{l}\text { Coordenador do centro } \\
\text { de treinamento }\end{array}$ & 1 & $44 \mathrm{~min} 32 \mathrm{~s}$ \\
\hline $\begin{array}{l}\text { Chefe da divisão de } \\
\text { operação e manutenção }\end{array}$ & 1 & $52 \mathrm{~min} 10 \mathrm{~s}$ \\
\hline Psicólogas & 2 & $1 \mathrm{~h} 26 \mathrm{~min}$ \\
\hline $\begin{array}{l}\text { Chefe da gerência } \\
\text { metropolitana }\end{array}$ & 1 & $25 \mathrm{~min} 27 \mathrm{~s}$ \\
\hline $\begin{array}{l}\text { Chefe do departamento } \\
\text { de meio ambiente }\end{array}$ & 1 & $22 \mathrm{~min} 42 \mathrm{~s}$ \\
\hline $\begin{array}{l}\text { Chefe do departamento } \\
\text { de SST }\end{array}$ & 1 & $1 \mathrm{~h}$ \\
\hline $\begin{array}{l}\text { Chefe de administração } \\
\text { geral e compras }\end{array}$ & 1 & $17 \min 42 \mathrm{~s}$ \\
\hline Supervisores & 5 & 1h30min \\
\hline Médica do trabalho & 1 & $54 \mathrm{~min} 29 \mathrm{~s}$ \\
\hline Assistente social & 1 & $21 \min 41 \mathrm{~s}$ \\
\hline Engenheiros de segurança & 2 & $2 \mathrm{~h}$ \\
\hline Técnicos de segurança & 5 & $2 \mathrm{~h} 06 \min 28 \mathrm{~s}$ \\
\hline $\begin{array}{l}\text { Funcionários do centro } \\
\text { de operações }\end{array}$ & 2 & $30 \mathrm{~min}$ \\
\hline Eletricistas & 95 & 9h56min29s \\
\hline Totais & 120 & $24 \mathrm{~h} 06 \min 14 \mathrm{~s}$ \\
\hline
\end{tabular}

reforma de redes de distribuição; (b) manutenções para prevenir a interrupção no fornecimento de energia; (c) manutenções de emergência, para re-estabelecer o fornecimento; (d) ligação, conectando clientes ao sistema de distribuição; e (e) corte, que corresponde ao desligamento de clientes do sistema (MELO et al., 2003).

A fragmentação das instalações físicas da empresa em diversas cidades, bem como seu grande porte, impôs limitações na coleta de dados, tais como:

(a) Coleta de dados centralizada na sede principal da empresa (capital do estado), uma vez que não houve recursos financeiros para realizar visitas às sedes do interior. Contudo, alguns eletricistas dessas filiais foram entrevistados, visto que estavam realizando cursos de treinamento na sede principal durante o período da pesquisa. Por esse motivo, as pontuações atribuídas a cada item do MASST assumiram a realidade da empresa como um todo, não estando associadas a determinada região de atuação da empresa;

(b) Exclusão das atividades do setor de teleatendimento e da rede de distribuição subterrânea, limitando a pesquisa à rede aérea.

\section{Modificações desenvolvidas no MASST}

\subsection{Estrutura para analisar os princípios da ER}

A forma mais simples de apresentar os resultados da avaliação, adotada no relatório de pesquisa entregue à empresa, corresponde à discussão das conclusões individualmente para cada item do MASST. Contudo, nesse formato, o atendimento aos princípios da ER aparece fragmentado ao longo dos diversos itens.

Tendo em vista disponibilizar uma estrutura analítica para que a perspectiva da ER seja explicitada nos resultados da avaliação, propõe-se que, a partir do relatório de resultados por item, sejam identificadas as fontes de resiliência e as fontes de fragilidades associadas ao SGSST. As fontes de resiliência devem ser interpretadas como todos os elementos do SGSST que contribuem para a manifestação das dimensões proativas e reativas da resiliência. Já as fontes de fragilidades devem ser interpretadas como todas as falhas do SGSST que prejudicam a resiliência. A palavra "fragilidade" é utilizada como tradução de brittleness, termo que os estudos pioneiros da ER (HOLLNAGEL; WOODS; LEVESON, 2006) tem proposto para expressar a propriedade oposta à resiliência, que torna o sistema incapaz de ser seguro e produtivo em um cenário de complexidade. Em relação às fontes de resiliência, propõe-se que a classificação das mesmas inclua as seguintes categorias:

(a) Identificação dos princípios da ER vinculados à fonte de resiliência: como situação desejável, cada fonte de resiliência deveria ter forte impacto em todos os princípios da ER;

(b) Ênfase proativa ou reativa: enquanto no primeiro caso a fonte de resiliência atua para evitar um acidente, no segundo caso ela atua para controlar os impactos do acidente e/ou recuperar o controle. A situação desejável é que a ênfase seja ao mesmo tempo proativa e reativa, ou que seja somente proativa;

(c) Resultado de ações formalmente planejadas ou de iniciativas informais: enquanto as ações formais constam no SGSST prescrito, as iniciativas informais emergem naturalmente a partir de adaptações realizadas pelos funcionários, sem que elas cheguem ao conhecimento de níveis hierárquicos superiores e sejam incorporadas pelo SGSST formal. A situação desejável é que a maior parcela possível de fontes de resiliência seja incorporada ao sistema formal. A existência de fontes emergentes normalmente significa que a capacidade adaptativa dos operadores está sendo usada para preencher lacunas no projeto do sistema, ao invés de estar sendo usada para otimizar bons projetos; 
(d) 0 subsistema sociotécnico que originou a fonte de resiliência: essa categoria permite identificar quais subsistemas vêm contribuindo para a resiliência do SGSST. De acordo com Hendrick e Kleiner (2001), os sistemas sociotécnicos são compostos por quatro subsistemas: (i) pessoal, compreendendo o perfil da força de trabalho como grau de especialização, características demográficas e aspectos psicossociais; (ii) técnico, que inclui características do ambiente físico e dos postos de trabalho, como grau de automação, ferramentas e máquinas; (iii) organização do trabalho, que se refere ao projeto dos níveis de complexidade, formalização e centralização; e (iv) ambiente externo, composto pelos ambientes socioeconômico, educacional, político, cultural e legal.

Uma fonte somente foi classificada como originada no subsistema pessoal quando ela partiu de iniciativas de grupos isolados de funcionários, sendo que colegas desempenhando funções similares não compartilhavam das mesmas práticas. Por exemplo, foi detectado que algumas equipes recusavam tarefa por falta de segurança, embora essa não fosse a situação típica da empresa. Caso todas (ou a maioria) as equipes adotassem boas práticas de recusas de tarefa, a fonte seria atribuída à organização do trabalho, visto que essa característica seria indício de políticas eficazes da empresa para tratar desse assunto. Nesse sentido, foi pressuposto que as fontes originadas no subsistema organização do trabalho necessariamente deveriam ser classificadas como formais. Por sua vez, as iniciativas de organização informal do trabalho foram associadas ao subsistema pessoal.

Em particular, foi importante definir os critérios citados para classificar as fontes originadas no subsistema pessoal, visto que em última instância todas as fontes foram originadas por decisões e/ou ações de pessoas posicionadas ao longo dos diversos níveis hierárquicos do sistema sociotécnico. Vale também salientar que uma fonte pode ter sido originada por mais de um subsistema, o que é coerente com o princípio de que existem relações de dependência entre os elementos de um sistema sociotécnico (CLEGG, 2000).

Em relação à situação desejável, é preferível que haja preponderância das fontes originadas na organização do trabalho, pelos mesmos motivos anteriormente citados que levam à preferência pelas fontes formais. De outro lado, as fontes originadas no ambiente externo deveriam ser as menos frequentes, visto que há menor grau de controle da empresa sobre esse subsistema.

Em relação às fontes de fragilidades, as categorias de análise foram similares, quais sejam: (a) Os princípios da ER que foram prejudicados. A situação relativamente mais grave ocorre quando todos os princípios foram fortemente prejudicados;

(b) A ênfase (proativa ou reativa) que deixou de existir em função da fonte de fragilidade. A situação relativamente menos grave ocorre quando uma ênfase reativa foi prejudicada;

(c) A origem da fonte de fragilidade, seja nos elementos formais do SGSST ou emergente das interações entre os elementos do sistema sociotécnico. Ambas as situações são consideradas igualmente indesejáveis, visto que muitas fragilidades associadas aos elementos formais indicam ineficácia da organização do trabalho e muitas fragilidades emergentes indicam a existência de interações complexas de difícil controle e antecipação;

(d) 0 subsistema sociotécnico no qual a fonte de fragilidades foi originada. Nesse caso, não é desejável a existência de muitas fontes associadas ao ambiente externo, devido à maior dificuldade de gerenciamento. Os critérios de classificação utilizados foram os mesmos adotados em relação às fontes de resiliência. Assim, uma fonte somente foi classificada como originada no subsistema pessoal quando foram identificados problemas de falta de capacitação, decisões ou ações inadequadas por parte de grupos específicos de funcionários. Por exemplo, houve reclamações de relações autoritárias entre chefes e subordinados, embora isso não possa ser generalizado para todas as equipes.

\subsection{Modificações nos procedimentos de aplicação do MASST}

Considerando as dificuldades percebidas pela equipe que aplicou o MASST no estudo de caso, foram desenvolvidas adaptações nos procedimentos originalmente propostos por Costella, Saurin e Guimarães (2009), quais sejam:

(a) Compilação das fontes de evidência de um mesmo tipo em listas específicas. Por exemplo, ao longo das 128 alíneas que estabelecem os requisitos de avaliação na versão original do MASST, 20 delas requerem observações diretas. Contudo, uma vez que tais alíneas estão distribuídas ao longo dos diversos itens, foi necessário identificar cada uma delas e estabelecer uma nova lista. 0 mesmo procedimento foi adotado para as demais fontes de evidências, incluindo a criação de listas específicas para cada categoria de entrevistado (por exemplo, técnicos de SST);

(b) Apresentação dos requisitos no formato de perguntas, ao invés de sentenças afirmativas. Tal mudança visou tornar mais fácil e rápido, 
especialmente para avaliadores com pouca experiência no método, a identificação do que deveria ser perguntado, observado ou analisado nos documentos;

(c) Uma vez que algumas alíneas incorporavam mais de um requisito em uma mesma sentença, houve uma reorganização para que cada alínea correspondesse somente a um requisito. Após essa mudança, o total de alíneas (agora transformadas em perguntas) do MASST passou de 128 para 150. No apêndice 1 podem ser encontrados exemplos de partes do instrumento de coleta de dados do MASST reformulado com base nas propostas apresentadas.

Essa modificação também contribuiu para reduzir a subjetividade na atribuição das pontuações, visto que um dos critérios para determiná-las é a quantidade de requisitos que foram atendidos. $\mathrm{Na}$ medida em que os requisitos são definidos com mais precisão (cada alínea sendo igual a um requisito), torna-se mais fácil determinar se eles são atendidos.

\subsection{Modificações na atribuição de pontuações}

Propõe-se que a atribuição de pontuações utilize as tabelas recomendadas pela FNQ (2009), visto que elas descrevem os critérios de avaliação em maiores detalhes (Quadro 3), comparativamente às tabelas da FPNQ (2006). De modo consistente com essa mudança, também foi adotado o procedimento de atribuição de pontos recomendado pela FNQ (2009), segundo o qual a pontuação do item é igual à pontuação do fator de menor avaliação, acrescido de 10 pontos caso pelo menos dois outros fatores estejam em estágio superior. Por exemplo, caso determinado item tenha pontuação igual a 20 segundo o fator de enfoque, mas pontuações superiores a isso segundo os demais fatores (aplicação, aprendizado e integração), a pontuação final do item será igual a 30.

Diferentemente da versão original do MASST, propõe-se que as pontuações não sejam expressas em percentuais, mas sim como valores absolutos. 0 uso de percentuais faz mais sentido na aplicação originalmente vislumbrada pelo Prêmio Nacional da Qualidade, na qual os percentuais são aplicados sobre pontuações máximas possíveis em cada item.

Tendo em vista reduzir a subjetividade na atribuição de pontuações ao fator enfoque (ver os critérios no Quadro 3), a avaliação de cada requisito do MASST foi classificada em uma dentre quatro categorias: requisito totalmente atendido, requisito parcialmente atendido, requisito não atendido, requisito não aplicável. Desse modo, a quantidade de requisitos atendidos pode ser calculada percentualmente, considerando que o atendimento total corresponde a 1 ponto, o atendimento parcial a 0,5 ponto e o não atendimento a zero ponto.

Entretanto, são necessárias melhorias em estudos futuros para reduzir a subjetividade de avaliação dos demais fatores da FNQ (2009), especialmente em relação ao fator integração, que trata da consistência das práticas de gestão da SST com as estratégias e objetivos organizacionais, bem como da interrelação entre as práticas. Enquanto a complexidade intrínseca a esse fator é o principal motivo da dificuldade de avaliação, sua importância sob a perspectiva sistêmica da ER justifica esforços adicionais para tornar a avaliação robusta.

Vale salientar que todos os fatores de avaliação da FNQ (2009) - enfoque, aplicação, aprendizado, integração) -, assim como os da FPNQ (2006), são alinhados com os princípios da ER, o que reforça a adequação do seu uso pelo MASST. São exemplos desse alinhamento as ênfases comuns da ER, da FNQ (2009) e da FPNQ (2006) na proatividade, na melhoria contínua, na disseminação das ações preventivas em todo o sistema sociotécnico e na integração entre todas as ações preventivas.

\subsection{Diretrizes para elaboração do plano de ação}

Os estudos anteriores não incluíram recomendações acerca de como desenvolver um plano de ação resultante da aplicação do MASST. Assim, propõe-se que a estrutura analítica apresentada no item 5.1 sirva como referência para o desenvolvimento do plano, na medida em que ela permite comparar as classificações desejáveis com as classificações reais de cada fonte de resiliência ou fragilidade, além de permitir a identificação de prioridades de atuação. Por exemplo, as fontes de fragilidades que prejudicam ênfases proativas podem ser priorizadas em relação às reativas, assim como as fontes originadas na organização do trabalho podem ser priorizadas em relação às fontes originadas no ambiente externo, visto que a atuação sobre essas últimas não depende somente da empresa avaliada.

Embora as fontes de resiliência que já foram enquadradas nas categorias desejáveis não necessitem ser incluídas no plano de ação, a empresa não deve adotar o pressuposto de que elas continuarão a ser fontes de resiliência no futuro. Isso estaria em conflito com um princípio fundamental adotado por organizações resilientes, 
Quadro 3. Quadro adaptada da FNQ (2009) para atribuir pontuações aos critérios 1 a 6 do MASST.

\begin{tabular}{|c|c|c|c|c|c|}
\hline 0 & 20 & 40 & 60 & 80 & 100 \\
\hline & \multicolumn{5}{|l|}{ Enfoque } \\
\hline $\begin{array}{l}\text { - As práticas } \\
\text { de gestão são } \\
\text { inadequadas } \\
\text { aos requisitos } \\
\text { do item ou não } \\
\text { estão relatadas. }\end{array}$ & $\begin{array}{l}\text { As práticas } \\
\text { de gestão } \\
\text { apresentadas } \\
\text { são adequadas } \\
\text { para algum(ns) } \\
\text { dos requisitos do } \\
\text { item. } \\
\end{array}$ & \begin{tabular}{|l} 
- As práticas \\
de gestão \\
apresentadas são \\
adequadas para \\
muitos requisitos \\
do item.
\end{tabular} & \begin{tabular}{|l} 
As práticas \\
de gestão \\
apresentadas são \\
adequadas para \\
a maioria dos \\
requisitos.
\end{tabular} & \begin{tabular}{|l} 
- As práticas \\
de gestão \\
apresentadas são \\
adequadas para \\
quase todos os \\
requisitos do \\
item.
\end{tabular} & \begin{tabular}{|l|} 
- As práticas \\
de gestão \\
apresentadas \\
são adequadas \\
a todos os \\
requisitos do \\
item. \\
\end{tabular} \\
\hline \multirow[t]{2}{*}{$\begin{array}{l}\text { - } 0 \text { atendimento } \\
\text { aos requisitos é } \\
\text { reativo. }\end{array}$} & $\begin{array}{l}\text { - } 0 \text { atendimento a } \\
\text { algum requisito é } \\
\text { proativo. }\end{array}$ & $\begin{array}{l}\text { - } 0 \text { atendimento a } \\
\text { muitos requisitos } \\
\text { é proativo. }\end{array}$ & $\begin{array}{l}\text { - } 0 \text { atendimento } \\
\text { à maioria dos } \\
\text { requisitos é } \\
\text { proativo. }\end{array}$ & $\begin{array}{l}\text { - } 0 \text { atendimento } \\
\text { a quase todos } \\
\text { os requisitos é } \\
\text { proativo. }\end{array}$ & 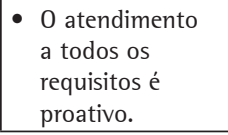 \\
\hline & \multicolumn{5}{|l|}{ Aplicação } \\
\hline $\begin{array}{l}\text { - As práticas } \\
\text { de gestão } \\
\text { apresentadas } \\
\text { não estão } \\
\text { disseminadas. }\end{array}$ & $\begin{array}{l}\text { - } 0 \text { conjunto } \\
\text { de práticas } \\
\text { de gestão } \\
\text { apresentadas } \\
\text { abrange alguma } \\
\text { das áreas, } \\
\text { processos, } \\
\text { produtos } \\
\text { ou partes } \\
\text { interessadas } \\
\text { pertinentes. } \\
\end{array}$ & $\begin{array}{l}\text { - } 0 \text { conjunto } \\
\text { de práticas } \\
\text { de gestão } \\
\text { apresentadas } \\
\text { abrange muitas } \\
\text { áreas, processos, } \\
\text { produtos } \\
\text { ou partes } \\
\text { interessadas } \\
\text { pertinentes. }\end{array}$ & $\begin{array}{l}\text { - } 0 \text { conjunto de } \\
\text { prática de gestão } \\
\text { apresentadas } \\
\text { abrange a } \\
\text { maioria das } \\
\text { áreas, processos, } \\
\text { produtos } \\
\text { ou partes } \\
\text { interessadas } \\
\text { pertinentes. }\end{array}$ & $\begin{array}{l}\text { - } 0 \text { conjunto } \\
\text { de práticas } \\
\text { de gestão } \\
\text { apresentadas } \\
\text { abrange quase } \\
\text { todas as áreas, } \\
\text { processos, } \\
\text { produtos } \\
\text { ou partes } \\
\text { interessadas } \\
\text { pertinentes. } \\
\end{array}$ & $\begin{array}{l}\text { - } 0 \text { conjunto } \\
\text { de práticas } \\
\text { de gestão } \\
\text { apresentadas } \\
\text { abrange todas as } \\
\text { áreas, processos, } \\
\text { produtos } \\
\text { ou partes } \\
\text { interessadas } \\
\text { pertinentes. }\end{array}$ \\
\hline \multirow[t]{2}{*}{ - Uso não relatado. } & $\begin{array}{l}\text { - Início de uso ou } \\
\text { uso continuado } \\
\text { de alguma } \\
\text { prática de gestão } \\
\text { apresentadas. } \\
\end{array}$ & $\begin{array}{l}\text { - Uso continuado } \\
\text { de muitas } \\
\text { das práticas } \\
\text { de gestão } \\
\text { apresentadas. } \\
\end{array}$ & \begin{tabular}{|l|} 
- Uso continuado \\
da maioria \\
das práticas \\
de gestão \\
apresentadas. \\
\end{tabular} & \begin{tabular}{|l|} 
- Uso continuado \\
de quase todas \\
as práticas \\
de gestão \\
apresentadas. \\
\end{tabular} & \begin{tabular}{|l|} 
- Uso continuado \\
de todas \\
as práticas \\
de gestão \\
apresentadas. \\
\end{tabular} \\
\hline & \multicolumn{5}{|l|}{ Aprendizado } \\
\hline \multirow[t]{2}{*}{$\begin{array}{l}\text { - Não há } \\
\text { melhorias sendo } \\
\text { implantadas; } \\
\text { e as práticas } \\
\text { de gestão } \\
\text { apresentadas } \\
\text { não demonstram } \\
\text { evidências de } \\
\text { refinamento. }\end{array}$} & $\begin{array}{l}\text { - Há melhorias } \\
\text { sendo } \\
\text { implantadas; ou } \\
\text { algumas práticas } \\
\text { de gestão } \\
\text { apresentadas são } \\
\text { refinadas. }\end{array}$ & $\begin{array}{l}\text { - Muitas práticas } \\
\text { de gestão } \\
\text { apresentadas são } \\
\text { refinadas. }\end{array}$ & $\begin{array}{l}\text { - A maioria } \\
\text { das práticas } \\
\text { de gestão } \\
\text { apresentadas é } \\
\text { refinada. }\end{array}$ & $\begin{array}{l}\text { - Quase todas } \\
\text { as práticas } \\
\text { de gestão } \\
\text { apresentadas } \\
\text { são refinadas } \\
\text { e espelham o } \\
\text { estado da arte } \\
\text { mundial. }\end{array}$ & $\begin{array}{l}\text { - Todas as práticas } \\
\text { de gestão } \\
\text { apresentadas } \\
\text { são refinadas } \\
\text { e espelham } \\
\text { o estado da } \\
\text { arte mundial; } \\
\text { alguma apresenta } \\
\text { uma inovação } \\
\text { de ruptura } \\
\text { representado um } \\
\text { novo referencial } \\
\text { de excelência. } \\
\end{array}$ \\
\hline & \multicolumn{5}{|l|}{ Integração } \\
\hline $\begin{array}{l}\text { - As práticas } \\
\text { de gestão } \\
\text { apresentadas } \\
\text { não são } \\
\text { coerentes com } \\
\text { as estratégias } \\
\text { e objetivos da } \\
\text { organização. }\end{array}$ & $\begin{array}{l}\text { - Quase todas } \\
\text { as práticas } \\
\text { de gestão } \\
\text { apresentadas são } \\
\text { coerentes com } \\
\text { as estratégias } \\
\text { e objetivos da } \\
\text { organização. }\end{array}$ & $\begin{array}{l}\text { - Todas as práticas } \\
\text { de gestão } \\
\text { apresentadas são } \\
\text { coerentes com } \\
\text { as estratégias } \\
\text { e objetivos da } \\
\text { organização; } \\
\text { quase todas } \\
\text { as práticas } \\
\text { de gestão } \\
\text { apresentadas } \\
\text { estão } \\
\text { interrelacionadas } \\
\text { com as outras } \\
\text { práticas de } \\
\text { gestão da } \\
\text { organização, } \\
\text { quando } \\
\text { apropriado. }\end{array}$ & $\begin{array}{l}\text { - Todas as práticas } \\
\text { de gestão } \\
\text { apresentadas } \\
\text { são coerentes } \\
\text { com estratégias } \\
\text { e objetivos da } \\
\text { organização } \\
\text { e estão } \\
\text { interrelacionadas } \\
\text { com outras } \\
\text { práticas de } \\
\text { gestão, havendo } \\
\text { cooperação } \\
\text { entre quase } \\
\text { todas as áreas } \\
\text { da organização } \\
\text { na sua } \\
\text { implementação, } \\
\text { quando } \\
\text { apropriado. }\end{array}$ & \begin{tabular}{|l} 
- Todas as práticas \\
de gestão \\
apresentadas \\
são coerentes \\
com estratégias \\
e objetivos da \\
organização \\
e estão \\
interrelacionadas \\
com outras \\
práticas de \\
gestão, havendo \\
cooperação \\
entre quase \\
todas as áreas \\
da organização \\
e com as partes \\
interessadas \\
pertinentes.
\end{tabular} & $\begin{array}{l}\text { - Plena integração } \\
\text { das práticas de } \\
\text { gestão; as áreas } \\
\text { da organização } \\
\text { trabalham em } \\
\text { harmonia entre si } \\
\text { e com as partes } \\
\text { interessadas } \\
\text { pertinentes, } \\
\text { contruindo } \\
\text { parcerias e } \\
\text { obtendo elevada } \\
\text { sinergia. }\end{array}$ \\
\hline
\end{tabular}


o qual lembra que não deve haver complacência mesmo que o desempenho seja momentaneamente bom, implicando em contínuo questionamento das práticas em uso (WEICK; SUTCLIFFE, 2001).

Também se sugere que, além de ações associadas especificamente a cada fonte de fragilidade ou resiliência, a avaliação seja concluída com recomendações de natureza estratégica, que induzam ao questionamento da filosofia de SST adotada pela empresa e sirvam de referência para as ações operacionais. Tanto as ações de natureza estratégica quanto operacional podem ser planejadas por meio de técnicas comumente usadas para elaborar planos de ação, como o 5W2H. Contudo, no caso de escolha de técnicas como essa, uma limitação intrínseca a ela, e relevante sob a perspectiva da ER, diz respeito à dificuldade de antecipar os impactos que cada ação tem sobre as demais.

\section{Aplicação das modificações propostas no estudo de caso}

\subsection{Análise do atendimento aos princípios da ER}

No estudo de caso, a análise segundo a estrutura proposta resultou na identificação de 17 fontes de resiliência e 47 fontes de fragilidades, as quais são parcialmente apresentadas nos Quadros 4 e 5. A aplicação das categorias para analisar as fontes de resiliência é ilustrada com base na fonte (5) listada no Quadro 4. Nesse caso, a resiliência se manifesta na comunicação informal que os eletricistas realizam acerca dos perigos, sendo que um exemplo diz respeito ao compartilhamento de informações acerca das áreas com maior risco de violência urbana, uma vez que são comuns as ameaças de clientes ou assaltos a eletricistas em certas regiões.
A contribuição dessa prática para implantar o princípio da consciência fica evidente na medida em que mais pessoas são informadas dos perigos. 0 princípio da aprendizagem também é colocado em prática, visto que a troca de informações decorre de sucessivas experiências de contato com determinados perigos - caso da violência urbana - ou do refinamento da percepção de riscos como decorrência da observação crítica do trabalho normal.

A ênfase dessa fonte é tanto proativa quanto reativa. Enquanto alguns dos perigos comunicados visam prevenir acidentes que ainda não ocorreram na empresa, outros podem ser comunicados como decorrência direta de sua contribuição em um acidente recente na empresa. Nesse último caso, a disseminação das informações tem caráter reativo, visto que foi destinada a recuperar o controle e evitar novas perdas após a ocorrência de um acidente.

Essa fonte de resiliência é emergente, uma vez que decorre de iniciativas espontâneas dos eletricistas para enfrentar as restrições impostas às suas atividades. Contudo, em função dessa característica, a comunicação de perigos tem impacto limitado a algumas equipes e a informação não fica registrada para fins de acúmulo de dados históricos e identificação de prioridades.

0 subsistema sociotécnico que originou essa fonte de resiliência é o subsistema pessoal, já que a iniciativa de comunicar perigos decorre da capacitação de alguns eletricistas, que perceberam essa necessidade. Um aspecto positivo dessa origem é que ela indica que os trabalhadores não estão resignados com a falta de procedimentos formais para comunicar perigos.

Considerando conjuntamente a análise de todas as fontes de resiliência, podem ser salientadas as seguintes conclusões: (a) 3 dentre as 17 fontes tiveram simultaneamente ênfase proativa e reativa, enquanto 13 tiveram ênfase apenas proativa; (b) 12 dentre as 17 fontes tiveram origem no sistema formal de gestão da SST e na organização

Quadro 4. Fontes de resiliência identificadas no estudo de caso.

\begin{tabular}{|l|c|c|c|c|}
\hline \multicolumn{1}{|c|}{ Fontes de resiliência } & $\begin{array}{c}\text { Principios da } \\
\text { ER implantados }\end{array}$ & $\begin{array}{c}\text { Ennfase da ER } \\
\text { estimulada }\end{array}$ & $\begin{array}{c}\text { Origem } \\
\text { emergente ou } \\
\text { formal? }\end{array}$ & $\begin{array}{c}\text { Subsistemas } \\
\text { sociotécnicos de } \\
\text { origem }\end{array}$ \\
\hline $\begin{array}{l}\text { (1) Política de SST com princípios de uma cultura } \\
\text { de segurança. }\end{array}$ & Todos & Proativa & Formal & $\begin{array}{c}\text { Organização do } \\
\text { trabalho }\end{array}$ \\
\hline $\begin{array}{l}\text { (2) Cursos aos eletricistas acerca de como se } \\
\text { relacionar com o consumidor. }\end{array}$ & $\begin{array}{c}\text { Consciência, } \\
\text { flexibilidade }\end{array}$ & Proativa & Formal & $\begin{array}{c}\text { Organização do } \\
\text { trabalho }\end{array}$ \\
\hline $\begin{array}{l}\text { (3) Adaptações devidas às características únicas de } \\
\text { cada tarefa. }\end{array}$ & Flexibilidade & Proativa & Emergente & $\begin{array}{c}\text { Ambiente externo, } \\
\text { técnico, pessoal }\end{array}$ \\
\hline $\begin{array}{l}\text { (4) Assistente social para reintegrar acidentados ao } \\
\text { trabalho. }\end{array}$ & Flexibilidade & Reativa & Formal & $\begin{array}{c}\text { Organização do } \\
\text { trabalho }\end{array}$ \\
\hline $\begin{array}{l}\text { (5) Comunicação informal de perigos entre as } \\
\text { equipes. }\end{array}$ & $\begin{array}{c}\text { Consciência, } \\
\text { aprendizagem }\end{array}$ & $\begin{array}{c}\text { Proativa e } \\
\text { reativa }\end{array}$ & Emergente & Pessoal \\
\hline
\end{tabular}


Quadro 5. Fontes de fragilidades identificadas no estudo de caso.

\begin{tabular}{|l|c|c|c|c|}
\hline \multicolumn{1}{|c|}{ Fontes de fragilidades } & $\begin{array}{c}\text { Principios da ER } \\
\text { prejudicados }\end{array}$ & $\begin{array}{c}\text { Enfase da ER } \\
\text { prejudicada }\end{array}$ & $\begin{array}{c}\text { Origem } \\
\text { emergente } \\
\text { ou formal? }\end{array}$ & $\begin{array}{c}\text { Subsistemas } \\
\text { sociotécnicos de } \\
\text { origem }\end{array}$ \\
\hline (1) Perigos organizacionais não são vistos como tais. & Consciência & Proativa & Formal & $\begin{array}{c}\text { Organização do } \\
\text { trabalho }\end{array}$ \\
\hline $\begin{array}{l}\text { (2) Critérios políticos por vezes se sobrepõem a critérios } \\
\text { técnicos na contratação de empresas terceirizadas. }\end{array}$ & Alta direção & Proativa & Emergente & $\begin{array}{c}\text { Ambiente } \\
\text { externo }\end{array}$ \\
\hline (3) Falta de diretrizes para realizar recusas de tarefa. & Alta direção & Proativa & Formal & $\begin{array}{c}\text { Organização do } \\
\text { trabalho }\end{array}$ \\
\hline $\begin{array}{l}\text { (4) Treinamentos são realizados em cenários distantes, } \\
\text { fisica e cognitivamente, dos cenários reais de trabalho. }\end{array}$ & $\begin{array}{c}\text { Consciência, } \\
\text { flexibilidade, } \\
\text { aprendizagem }\end{array}$ & Proativa e \\
reativa & Formal & $\begin{array}{c}\text { Organização do } \\
\text { trabalho, técnico, } \\
\text { ambiente externo }\end{array}$ \\
\hline $\begin{array}{l}\text { (5) Falta de ampla e imediata disseminação de } \\
\text { informações resultantes das investigações de acidentes. }\end{array}$ & $\begin{array}{c}\text { Consciência, } \\
\text { aprendizagem }\end{array}$ & Reativa & Formal & $\begin{array}{c}\text { Organização do } \\
\text { trabalho }\end{array}$ \\
\hline
\end{tabular}

do trabalho, o que é condizente com o foco do MASST em avaliar o sistema formal ao invés do sistema informal; (c) o ambiente externo contribuiu como origem em apenas 1 das fontes, o que pode ser considerado positivo; e (d) o subsistema pessoal contribuiu como origem em 6 das 17 fontes, indicando que os eletricistas desenvolvem estratégias adaptativas para preencher lacunas no projeto do sistema sociotécnico.

Já a aplicação das categorias de análise das fontes de fragilidades é ilustrada com base na fonte (4) listada no Quadro 5. Ao longo da avaliação, as evidências indicaram que os treinamentos eram realizados em ambientes fisica e cognitivamente distantes dos cenários reais de trabalho. Embora a empresa possua um centro de treinamento que é referência para muitos concorrentes, os postes em que as tarefas são treinadas apresentam condições físicas mais favoráveis do que naqueles encontrados nas ruas. Por exemplo, não são encontradas ligações clandestinas, fiações de telefones, postes podres, terrenos irregulares, dentre outros. Além disso, os treinamentos não reconstituem o contexto organizacional real das tarefas, com as demandas cognitivas decorrentes, no caso, de pressões de tempo ou defeitos imprevistos nos equipamentos. Essas evidências demonstram que os cenários de treinamento presumem baixa variabilidade nas tarefas de campo, ao invés de expor os eletricistas à alta variabilidade do trabalho real.

Tais problemas prejudicam três princípios da ER. A consciência e a aprendizagem são prejudicadas, pois a baixa fidelidade das simulações dificulta a identificação dos limites do trabalho seguro durante as tarefas em condições reais. A flexibilidade é danificada uma vez que as limitações dos treinamentos tornam os eletricistas mais dependentes de supervisão de colegas experientes.

Essa fonte de fragilidade prejudica tanto a ênfase proativa quanto a reativa. De um lado, as limitações nos treinamentos dificultam que o eletricista antecipe situações de perigo e previna acidentes. De outro lado, a ênfase reativa é prejudicada visto que as mesmas limitações nos treinamentos podem dificultar a realização de primeiros-socorros em colegas acidentados (por exemplo, o resgate de acidentados em postes com obstáculos é mais difícil que em postes sem obstáculos), bem como prejudicar a minimização de impactos de acidentes a consumidores e ao público em geral.

As deficiências citadas nos treinamentos podem ser associadas ao sistema formal de gestão da SST, uma vez que existe na empresa uma infraestrutura física e humana dedicada em tempo integral à gestão dos treinamentos. Como aspecto positivo, isso indica que há recursos para desenvolver melhorias.

Três dentre os quatro subsistemas sociotécnicos contribuíram para originar essa fonte de fragilidade:

(a) A organização do trabalho, pelo planejamento inadequado dos treinamentos;

(b) 0 subsistema técnico e o ambiente externo, responsáveis pela grande variedade de cenários nos locais de trabalho, o que cria dificuldades para que esta seja incorporada pelos cenários de treinamento. Para essa fonte de fragilidade, o subsistema pessoal arca com as consequências das restrições impostas pelos demais subsistemas, não sendo a origem das fragilidades.

Considerando conjuntamente todas as fontes de fragilidades, podem ser salientadas as seguintes conclusões:

(a) 41 dentre as 47 fontes prejudicaram ênfases proativas;

(b) 42 dentre as 47 fontes tiveram origem no sistema formal de gestão da SST e na organização do trabalho, o que indica que a eliminação delas passa pela melhoria das ferramentas de gestão já existentes na empresa; 
(c) Os subsistemas técnico e pessoal normalmente sofrem as consequências de falhas nos demais subsistemas, não sendo origens frequentes. 0 subsistema pessoal contribuiu como origem de apenas três fontes e o técnico de apenas sete fontes. Em termos comparativos, isso indica que a variabilidade do desempenho humano contribuiu com maior frequência para gerar resiliência do que para gerar fragilidades. De fato, o subsistema pessoal contribuiu em 35\% das fontes de resiliência e em apenas 6\% das fontes de fragilidades;

(d) Embora o ambiente externo tenha contribuído para originar apenas cinco fontes, todas elas prejudicam o comprometimento da alta direção. Nesse sentido, a avaliação deixou claro que não existem mecanismos para garantir a continuidade das ações de gestão da SST sob uma perspectiva de longo prazo. Por sua vez, isso decorre da alta rotatividade nos cargos de direção devido a interesses de partidos políticos que se alternam no governo estadual, o principal acionista da empresa.

\subsection{Pontuações atribuídas no estudo de caso}

A Tabela 2 apresenta as pontuações que cada item obteve no estudo de caso, tanto segundo critérios da FPNQ (2006) quanto conforme os da FNQ (2009). É possível observar que a maior parte das pontuações permaneceu idêntica, embora para alguns itens a avaliação segundo a FNQ (2009) tenha sido de 10 a 20 pontos inferior à pontuação obtida por meio da FPNQ (2006).

A Tabela 2 também apresenta as pontuações obtidas no estudo de Costella, Saurin e Guimarães (2009), para fins de comparação com os resultados obtidos por meio dos critérios da FPNQ (2006). É provável que o melhor desempenho da empresa investigada por Costella, Saurin e Guimarães (2009) em itens como documentação e registros, auditorias internas e condução de análise crítica e melhoria contínua se deva ao fato de aquela empresa possuir

Tabela 2. Pontuações e comparação com outra empresa na qual o MASST foi aplicado.

\begin{tabular}{|c|c|c|c|}
\hline Item & $\begin{array}{c}\text { EC* }^{*} \\
\text { (FPNQ, 2009) }\end{array}$ & $\begin{array}{c}\text { EC }^{*} \\
\text { (FPNQ, 2006) }\end{array}$ & $\begin{array}{c}\text { Costella, Saurin e } \\
\text { Guimarães (2009) } \\
(\%)\end{array}$ \\
\hline 1.1 - Objetivos e política do SGSST & 20 & 20 & 10 \\
\hline 1.2 - Planejamento do SGSST & 10 & 10 & 20 \\
\hline 1.3 - Estrutura e responsabilidade & 10 & 10 & 0 \\
\hline 1.4 - Documentação e registros & 20 & 20 & 70 \\
\hline 1.5 - Requisitos legais & 40 & 40 & 70 \\
\hline 1.6 - Compromisso de alta direção & 20 & 20 & 0 \\
\hline 2.1 - Identificação de perigos com enfoque tradicional & 40 & 50 & 40 \\
\hline 2.2 - Identificação de perigos com enfoque na ER & 10 & 20 & 0 \\
\hline 2.3 - Avaliação de riscos & 10 & 10 & 0 \\
\hline 2.4 - Planejamento de ações preventivas com enfoque na ER & 10 & 10 & 10 \\
\hline 3.1 - Participação dos trabalhadores & 30 & 30 & 30 \\
\hline 3.2 - Treinamento e capacitação & 50 & 50 & 50 \\
\hline 4.1 - Integração de sistemas de gestão & 0 & 0 & 0 \\
\hline 4.2 - Gerenciamento das mudanças & 10 & 30 & 0 \\
\hline 4.3 - Manutenção & 20 & 30 & 50 \\
\hline 4.4 - Aquisição e contratação & 50 & 50 & 0 \\
\hline 4.5 - Fatores externos & 20 & 30 & 0 \\
\hline 5.1 - Indicadores reativos & 20 & 20 & 30 \\
\hline 5.2 - Indicadores proativos & 20 & 20 & 0 \\
\hline 5.3 - Auditoria interna & 0 & 0 & 30 \\
\hline 6.1 - Investigação de incidentes & 30 & 30 & 30 \\
\hline 6.2 - Investigação do trabalho normal & 0 & 0 & 0 \\
\hline 6.3 - Ações preventivas & 0 & 0 & 0 \\
\hline 6.4 - Ações corretivas & 0 & 0 & 20 \\
\hline 6.5 - Condução da análise crítica e melhoria contínua & 10 & 10 & 30 \\
\hline 7.1 - Desempenho reativo & 10 & 10 & 10 \\
\hline 7.2 - Desempenho proativo & 0 & 0 & 0 \\
\hline Média & 17,1 & 19,3 & 19,6 \\
\hline
\end{tabular}


certificação ISO 9001, a qual exige padronização e formalização de atividades gerenciais.

No caso da distribuidora de energia elétrica, pontuações melhores não foram obtidas principalmente pelo fato de que as práticas observadas atendiam poucos dos requisitos. De fato, 23 dos 28 itens avaliados foram enquadrados nas linhas A ou B das tabelas da FPNQ (2006) (Quadro 2). De acordo com a lógica do sistema de pontuação, esse enquadramento significa que nenhum ou menos da metade dos requisitos foram atendidos, o que limita as notas ao valor máximo de 30\%.

Além disso, nenhum item foi classificado nas colunas 4 ou 5 das tabelas da FPNQ (2006), o que permitiria obter pontuações acima de 70\%. Essa classificação não ocorreu visto que as práticas observadas, quando atendiam aos requisitos, não estavam disseminadas em todas as áreas da empresa e/ou não vinham sendo usadas consistentemente há vários anos e/ou não eram integradas com os demais elementos do SGSST. Como exemplo de prática sem continuidade ao longo de vários anos, pode ser citado o fornecimento de equipamentos de proteção individual (EPI), visto que poucos meses antes do início do estudo houve falta generalizada de EPI. Além disso, não foram detectadas estratégias de longo prazo que garantam que as boas práticas atuais serão mantidas. A avaliação apontou que algumas boas práticas foram implantadas recentemente e em parte como reação a uma série de acidentes graves.

Vale também destacar que membros do departamento de SST apresentaram resistência em aceitar as baixas pontuações obtidas. Na percepção dos pesquisadores, tal resistência devia-se tanto ao temor de eventuais retaliações por parte da direção quanto à falta de compreensão acerca dos rigorosos critérios do sistema de pontuação. Esse último problema foi controlado por meio de explicações detalhadas e a revisão de algumas notas em conjunto com os representantes da empresa.

\subsection{Ações resultantes da avaliação no estudo de caso}

Assim como nos estudos anteriores de aplicação do MASST, no presente estudo também não foi desenvolvido um plano de ação para tratar de cada oportunidade de melhoria identificada. Similarmente aos estudos anteriores, os representantes das empresas não manifestaram interesse em desenvolver tal plano, possivelmente porque a SST não era um valor enraizado na cultura organizacional e um eventual plano não obteria recursos para sua plena implantação.
Contudo, em coerência com a proposta apresentada no item 5.4 deste artigo, houve recomendações de natureza estratégica e operacional à empresa. Como exemplos das recomendações estratégicas, podem ser destacadas as seguintes:

(a) A SST deve ser entendida como um valor chave, ao invés de prioridade em determinados períodos. A priorização eventual ficou evidente durante a avaliação, visto que poucos meses antes de seu início houve uma série de acidentes fatais com eletricistas, o que levou a ações isoladas para tratar de condições latentes graves como a falta de EPI;

(b) Há necessidade de disseminar conhecimentos mínimos sobre gestão de SST em todas as áreas e níveis hierárquicos da empresa, como parte de uma estratégia para integração da SST com as demais áreas. Como exemplo dessa necessidade, a avaliação identificou oportunidades de ampliar a integração com a área de engenharia, para que esta realize uma análise de SST em mudanças tecnológicas de qualquer natureza, não só naquelas ligadas a equipamentos de segurança.

Embora não tenha sido elaborado um plano de ação formal, dois novos projetos de pesquisa foram iniciados na empresa como decorrência das conclusões obtidas por meio do MASST, caracterizando ações de natureza operacional. Tais projetos começaram imediatamente após a conclusão da avaliação e abordaram os seguintes temas:

(a) Projeto, implantação e avaliação de um sistema de relatos de informações de SST. Esse tema foi escolhido em função de seu impacto em diversos elementos do SGSST, gerando contribuições como as seguintes: subsidiar o estabelecimento de objetivos de SST, ampliar as oportunidades de participação dos funcionários, priorizar as ações de controle de perigos, gerar dados que possam constituir indicadores proativos (por exemplo, número de relatos mensais por funcionário);

(b) Projeto, implantação e avaliação de treinamentos que simulem com maior fidelidade as condições reais de trabalho, com base em técnicas da análise de tarefas cognitivas (CRANDALL; KLEIN; HOFFMAN, 2006). Diferentemente do sistema de relatos de informações de SST, o impacto desse projeto é mais limitado ao subsistema pessoal, embora não seja menos importante. 0 pressuposto adotado foi de que, independente de quaisquer melhorias na organização do trabalho ou em tecnologias, a natureza das atividades dos eletricistas requer constantes investimentos em capacitação das equipes. Isso se deve ao fato de que as atividades são realizadas em ambiente dinâmico e sujeito a restrições difíceis de serem completamente antecipadas e eliminadas por meio de procedimentos formais. 


\section{Conclusões}

Este estudo apresentou propostas para melhorias de um método de avaliação de SGSST que explicitamente adota um paradigma de gestão da SST denominado engenharia de resiliência (ER). As propostas visam controlar tanto dificuldades identificadas nos estudos anteriores de aplicação do MASST quanto dificuldades que surgiram ao longo do estudo de caso em uma distribuidora de energia elétrica. É importante salientar que as modificações no método não foram decorrentes de características intrínsecas ao setor investigado, o que é um indício de possibilidade de generalização da aplicação do MASST para setores diferentes daquele em que ele foi originalmente desenvolvido.

Quatro principais modificações no MASST foram propostas. A primeira delas diz respeito a uma estrutura analítica para facilitar a análise dos resultados explicitamente segundo os princípios da ER. Essa análise possui um nível de abstração maior em comparação à análise realizada item a item do MASST, cuja existência é um pré-requisito para aplicar a estrutura proposta. A aplicação da estrutura analítica no estudo de caso indicou que o MASST permite a identificação de fontes de resiliência e de fragilidade em qualquer elemento do sistema sociotécnico.

Contudo, a ênfase do MASST nos elementos formais de um SGSST fez com que as fontes emergentes de resiliência e fragilidade fossem identificadas de modo superficial, requerendo outros métodos de investigação para serem mais bem compreendidas. Outro pressuposto é que a quantidade de fontes emergentes é maior que aquela passível de identificação por meio do MASST. De fato, cabe reconhecer que mesmo as fontes formais de resiliência e fragilidades identificadas por meio do MASST não são investigadas em profundidade, visto que a grande abrangência do método exigiria dispêndio correspondente de recursos humanos para completa investigação.

A segunda proposta de modificação tem fortes vínculos com a anterior, uma vez que foi sugerido que o plano de ação seja desenvolvido a partir da aplicação da estrutura analítica que explicita os vínculos com a ER. Em particular, propõe-se que o plano de ação vise eliminar as diferenças entre as classificações desejáveis e as classificações reais de cada fonte de resiliência ou fragilidade.

A terceira e a quarta propostas têm natureza mais operacional que as demais. O objetivo da terceira proposta foi facilitar o uso do instrumento de pesquisa por parte de avaliadores com pouca experiência no método, por meio da apresentação dos requisitos no formato de perguntas que tratassem de um requisito de cada vez.
A quarta proposta visou tornar menos subjetiva, em comparação à versão original do MASST, a atribuição das pontuações. Assim, foi adotada uma nova tabela e foram atribuídos graus de atendimento a cada requisito, tendo em vista facilitar o cálculo do percentual de atendimento, que era uma exigência do sistema de pontuação usado. Apesar de o sistema de pontuação ainda permanecer subjetivo, seu uso justifica-se na medida em que há alinhamento dos critérios de atribuição de notas com os princípios da ER, além de que a natureza não prescritiva é intrínseca à filosofia sociotécnica que embasa a ER.

Como sugestões de estudos futuros, podem ser salientadas: (a) a aplicação do MASST em novos contextos e por outros pesquisadores, o que permitirá investigar se há necessidade de novas adaptações no mesmo; (b) a aplicação periódica do MASST em uma mesma empresa, visando identificar o quanto o método contribui para a melhoria do desempenho e o quanto as fontes de resiliência e fragilidades mudam ao longo do tempo; (c) o uso de métodos já existentes (por exemplo, mapas conceituais), ou o desenvolvimento de novos métodos que permitam a análise dos relacionamentos entre os itens do MASST, explicitando como o desempenho em determinado item impacta nos demais - devido à grande quantidade de itens, a análise dos relacionamentos entre eles pode ser inicialmente limitada às interfaces entre os itens pertencentes a um mesmo critério; (d) a aplicação do MASST em paralelo com outros métodos que visem avaliar a resiliência em outras dimensões da organização (por exemplo, trabalho em equipe), ou que procurem fontes de resiliência e fragilidade sem foco em uma dimensão predeterminada. Tais estudos podem proporcionar uma avaliação de resiliência mais profunda e permitir a investigação de vínculos causais entre diferentes fontes e tipos de resiliência.

\section{Referências}

CARIM JÚNIOR, G.; SILVA, M.; SAURIN, T. A. Auditoria de saúde e segurança no trabalho sob o enfoque da engenharia de resiliência: estudo de caso em uma empresa de aviação civil. In: SIMPÓSIO DE ENGENHRIA DE PRODUÇÃO, 15., 2008, Bauru. Anais... Bauru: UNESP, 2008. Disponivel em: <http://www.simpep.feb.unesp.br/ anais.php>. Acesso em: dez. 2008.

CLEGG, C. Sociotechnical principles for system design. Applied Ergonomics, v. 31, p. 463-477, 2000.

COSTELLA, M.; SAURIN, T. A.; GUIMARÃES, L. B. M. A method for assessing health and safety management systems from the resilience engineering perspective. Safety Science, v. 47, n. 8, p. 1056-1067, 2009.

CRANDALL, B.; KLEIN, G.; HOFFMAN, R. Working minds: a practitioner's guide to cognitive task analysis. Cambridge: MIT Press, 2006. 
DEKKER, S.; WOODS, D. The high reliability organization perspective. In: SALAS, E.; MAURINO, D. (Eds.). Human Factors in Aviation. 2 ed. San Diego: Elsevier, 2010. p. 123-144.

DEKKER, S. The Field Guide to Human Error Investigations. London: Ashgate, 2002.

FUNDAÇÃO PARA O PRÊMIO NACIONAL DA QUALIDADE FPNQ. Critérios de excelência: o estado da arte da gestão para a excelência do desempenho. São Paulo, 2006. Disponível em: <http://www.fpnq.org.br/criterios_2006. htm>. Acesso em: out. 2006.

FUNDAÇÃO NACIONAL DA QUALIDADE - FNQ. Critérios de excelência: avaliação e diagnóstico da gestão organizacional. São Paulo, 2008. Disponível em: <http:// www.fnq.org.br/Portals/_FNQ/Documents/Critérios_ Excelência_2009.pdf>. Acesso em: out. 2009.

HALE, A. R.; GULDENMUND, F.; GOOSSENS, L. Auditing resilience in risk control and safety management systems. In: HOLLNAGEL, E.; WOODS, D.; LEVESON, N. (Eds.). Resilience engineering: concepts and precepts. London: Ashgate, 2006. p. 270-295.

HENDRICK, H. W.; KLEINER, B. M. Macroergonomics: an introduction to work system design. Santa Monica: Human Factors and Ergonomics Society, 2001.

HOLLNAGEL, E.; NEMETH, C.; DEKKER, S. Resilience engineering perspectives: remaining sensitive to the possibility of failure. Burlington: Ashgate, 2008. (v. 1)

HOLLNAGEL, E.; WOODS, D.; LEVESON, N. Resilience engineering: concepts and precepts. London: Ashgate, 2006.

HOLLNAGEL, E.; WOODS, D. Joint cognitive systems. an introduction to cognitive systems engineering. London: Taylor and Francis, 2005.
HOLLNAGEL, E.; WOODS, D. Cognitive systems engineering: new wine in new bottles. International Journal of Human-Computer Studies, v. 51, p. 339-356, 1999.

LUNDBERG, J.; ROLLENHAGEN, C.; HOLLNAGEL, E. What-you-look-for-is-what-you-find: the consequences of underlying accident models in eight accident investigation manuals. Safety Science, v. 47, n. 10 p. 1297-1311, 2009.

REIMAN, T.; OEDEWALD, P. Evaluating safety-critical organizations. emphasis on the nuclear industry. Espoo: Technical Research Center of Finland, 2009. (Report number 2009:12)

MELO, L. et al. Segurança em serviços emergenciais em redes elétricas: os fatores ambientais. Revista Produção, v. 13, n. 2, p. 88-101, 2003.

REASON, J. Managing the risks of organizational accidents. Burlington: Ashgate, 1997.

WEICK, K.; SUTCLIFFE, K. Managing the unexpected: assuring high performance in an age of complexity. San Francisco: Jossey-Bass, 2001.

WESTRUM, R. Resilience typology. In: HOLLNAGEL, E.; WOODS, D.; LEVESON, N. (Eds.). Resilience engineering: concepts and precepts. London: Ashgate, 2006. p. 49-59.

\section{Agradecimentos}

Os autores agradecem aos demais membros da equipe de pesquisadores que colaboraram na coleta de dados, quais sejam: Carlo Chanin, Giovanni Susin, Lívia Silva Paranhos, Luciane Lacerda Gomes, Priscila Wachs, Renata Cornelli.

\title{
Proposals of improvements to a method for assessing health and safety management systems
}

\begin{abstract}
This article presents proposals for improvements of a method for assessing health and safety management systems. This method has resilience engineering (RE) as its underlying philosophy and it was originally devised and tested in a case study of a manufacturing plant. Four changes were proposed in comparison with the original version of the method: (a) guidelines for assessing the use of RE principles more systematically; (b) guidelines for developing an action plan as a result of the assessment; (c) re-organization of the data collection tools in order to make it easier for use by inexperienced auditors; and (d) procedures for facilitating the assignment of scores to the items assessed. The impact of these changes is illustrated by means of a case study in which the method was applied in a company that distributes electrical energy. The changes in the method were not made as a result of the particularities of the company involved in the case study, which is an indication of possible application of the method in other sectors, beyond manufacturing.
\end{abstract}

\section{Keywords}

Health and safety management. Resilience engineering. Electricians. 


\section{Apêndice 1. Extratos do instrumento de avaliação revisado do MASST.}

\section{Planejamento de ações preventivas com enfoque na ER}

\section{Abordagem: estrutural e operacional}

Fontes de evidências: observações diretas (requisitos a, h), análise de documentos (requisitos b, e, f, g, i), entrevista com representantes da alta direção (requisitos g, d, f), entrevista com gerente de produção (todos os requisitos), entrevista com representantes do setor de SST (todos os requisitos), entrevista com trabalhadores (todos os requisitos, com exceção de $\mathrm{g}, \mathrm{h})$.

(a) É realizado o monitoramento da conformidade com os procedimentos de SST e produção (flexibilidade, consciência e aprendizagem)? Descreva como o monitoramento é realizado (periodicidade, responsável, disseminação dos resultados etc.).

*0 avaliador deve observar o trabalho real em um ou mais postos de trabalho, comparando-o com o trabalho prescrito, tendo em vista identificar necessidades de adaptações de procedimentos e situações não previstas.

(b) Há diretrizes documentadas acerca de como realizar a melhoria contínua dos procedimentos de SST e produção (flexibilidade e aprendizagem)? Consulte tais documentos e descreva as principais diretrizes.

(c) Os trabalhadores têm autonomia para tomar decisões com impacto na SST (flexibilidade e consciência)? Cite exemplos dessas decisões.

(d) Os trabalhadores têm autonomia para paralisar a produção caso eles percebam uma situação como sendo de grave e iminente risco (flexibilidade e consciência)? Cite exemplos.

(e) Há registros documentados das decisões que paralisam a produção em favor da segurança (flexibilidade, aprendizagem e consciência)? Consulte tais documentos e verifique se os registros são de fácil compreensão e podem gerar informações úteis para a construção de indicadores de desempenho.

(f) Há diretrizes documentadas acerca dos passos a serem adotados para que os trabalhadores recusem uma tarefa por falta de segurança (flexibilidade)? Consulte tais documentos e verifique se o processo de recusa é excessivamente burocrático. (g) As ações preventivas têm visão sistêmica, incluindo ações para o controle de perigos associados à organização do trabalho e que podem ser originados em processos administrativos, como gestão de compras, gestão de custos, gestão de recursos humanos etc. (comprometimento da alta direção e aprendizagem)? Consulte os procedimentos de SST e produção e identifique exemplos desses tipos de ações preventivas.

(h) Há planejamento sistemático de barreiras contra acidentes caracterizadas pelo uso de dispositivos à prova de erros (flexibilidade)?

*0 avaliador deve observar uma ou mais dessas barreiras em operação, verificando, dentre outros aspectos, se há um plano de manutenção, se o grau de controle exercido é compatível com o risco, quais os tipos de falhas que justificaram o uso da barreira.

(i) Os procedimentos de SST e produção apresentam recomendações para que os trabalhadores recuperem o controle após desvios indesejados (flexibilidade e consciência)? Consulte os procedimentos e identifique exemplos.

\section{Participação dos trabalhadores}

\section{Abordagem: operacional}

Fontes de evidências: entrevista com representantes do setor de SST (requisitos a, b), entrevista com trabalhadores (requisitos a, b), observações diretas (requisito a).

(a) Há modalidades formais e informais de participação dos trabalhadores na gestão da SST -por exemplo, sistemas de sugestões, CIPA, reuniões diárias de SST, treinamentos etc. (todos os princípios da ER)? Descreva cada modalidade.

*0 avaliador deve participar como observador de alguns dos eventos formais de participação, como CIPA e treinamentos.

(b) Existem mecanismos, formais e informais, para que as opiniões dos trabalhadores sejam levadas em conta no projeto de procedimentos de produção e SST (todos os princípios da ER)? Descreva cada mecanismo. 